\title{
SOBRE AS AUTORAS E OS AUTORES
}

\section{Angela Elisabeth Lühning}

Possui doutorado em Vergleichende Musikwissenschaft - Freie Universität Berlin (1989) e graduação em Licenciatura de instrumento (violoncelo) Musikhochschule Detmold/ Alemanha (1982). Atua desde 1990 no Programa de Pós-graduação em Música, PPGMUS, da EMUS/ UFBA, desde 2005 no Programa multidisciplinar de Pós-graduação em Estudos étnicos e africanos, PósAfro, do CEAO/ UFBA. Pós-doutorado em História (UFBA), 2012. É professora titular da Escola de Música (EMUS) da Universidade Federal da Bahia e diretora secretária da Fundação Pierre Verger, responsável pela coordenação do Espaço Cultural Pierre Verger, voltado para a prática e inserção da cultura afro-brasileira nas comunidades vizinhas. Tem experiência na área de Artes e Cultura, com ênfase em etnomusicologia/ antropologia/educação musical, atuando principalmente no âmbito dos seguintes temas: etnomusicologia participativa, cultura afro-brasileira, processos de transmissão, músicas brasileiras em contextos históricos e contemporâneos, culturas comunitárias urbanas, relações escolas públicas e culturas comunitárias, além de Pierre Fatumbi Verger e sua obra.

\section{Ari Lima}

Possui graduação em Comunicação Social pela Universidade Federal da Bahia (1990), mestrado em Comunicação e Cultura pela Universidade Federal do Rio de Janeiro (1995) e doutorado em Antropologia Social pela Universidade de Brasília (2003). Atualmente é Professor Titular e Professor Permanente do Programa de Pós-Graduação em Crítica Cultural da Universidade do Estado da Bahia (UNEB). Coordenador do Núcleo das Tradições Orais e Patrimônio Imaterial (NUTOPIA/ Campus II/UNEB). Tem experiência na área de Antropologia, com ênfase em Antropologia das Populações Afro-Brasileiras, atuando nos seguintes temas: relações raciais, patrimônio imaterial, música, culturas populares e negras. Tem atuado como pesquisador ou consultor em vários projetos de extensão sobre culturas populares e negras, tal como, o inventário sobre o samba de roda do Recôncavo baiano encomendado pelo IPHAN (2005) e o Projeto Cantador de Chula. Compõe a equipe de pesquisadores do Instituto Nacional de Inclusão Étnica e Racial no Ensino Superior e na Pesquisa financiado pelo CNPq e MCT e é membro do GT de Literatura Oral e Popular da ANPOLL desde 2012.

Pontos de Interrogaçầo, v. 8, n. 2, jul.-dez., 2018. 


\section{Caio Csermak}

Possui graduação em Relações Internacionais pela Universidade de Brasília (2009). É mestre em Antropologia Social pela Universidade de Brasília (2013) e Especialista doutorando em Antropologia Social pela Universidade de São Paulo. Foi assistente de programas do Fundo de Desenvolvimento das Nações Unidas para a Mulher, atual ONU Mulheres, ambas instituições integrantes do Sistema Nações Unidas. Atuou também como animador cultural na área de programação musical do Serviço Social do Comércio do Estado de São Paulo, assim como também assume o papel de produtor cultural e curador de música em projetos diversos. Tem experiência nas áreas de Ciência Política, Relações Internacionais, Musicologia, Políticas Públicas, Produção Cultural e Antropologia, com os temas: gênero e orçamento público, sociedade civil, Sistema ONU, políticas culturais, cultura popular, patrimônio cultural imaterial, etnomusicologia, relações raciais e antropologia visual. Membro da Associação Internacional para o Estudo da Música Popular - seção América Latina (IASPM-AL).

\section{Cassio Leonardo Nobre de Souza Lima}

Mestrado e Doutorado em Etnomusicologia (UFBA, 2008; 2017), Bacharel em História (UFBA, 2001), além de músico, compositor, produtor musical e gestor cultural. Em 22 anos de carreira artística, acompanhou e colaborou com inúmeros artistas da música popular da Bahia. Entre 2007-2015, lançou quatro álbuns autorais, dentre eles, o "Viola de Arame", que explora as possibilidades sonoras experimentais das violas brasileiras de 10 cordas. Em 2010, recebeu o Prêmio Palmares de Dissertação sobre a Cultura Afro Brasileira, e a Bolsa Funarte de Produção Cultural para Internet, para o seu segundo trabalho autoral. Entre 2011 a 2015, foi coordenador de Música da Fundação Cultural do Estado da Bahia (Funceb), e prestou consultorias para diversas ações e projetos do governo da Bahia. Contemplada no IV Prêmio Afro 2017, produziu com Xavier Vatin o projeto de pesquisa "Memórias Afro-Atlânticas: as gravações de Lorenzo Turner na Bahia (1940-1941)", lançado em livro/CD e na internet. 


\section{Charles Alexander Exdell}

Possui graduação em Letras - Espanhol e Estudos Latinoamericanos pela Universidade de Kansas (2005) e mestrado em Música - Etnomusicologia pela UFBA (2017). Atualmente doutorando em Etnomusicologia na Indiana University in Bloomington, aprofundando suas pesquisas sobre os muitos sambas nos sertões baianos.

\section{Fernanda Castro de Queiroz}

Mestranda no Programa de Pós-Graduação em Antropologia pela Universidade Federal da Bahia (UFBA), Graduação em Jornalismo pela Universidade Estadual do Sudoeste da Bahia (UESB), especialista em Comunicação e Política pela mesma instituição. Tem experiência na área de Jornalismo, Produção Cultural, com especial interesse pela área da Antropologia, Gênero, Patrimônio e Samba de Roda.

\section{Gustavo Gobbi Novaes}

Graduação em História pela Universidade Federal de Juiz de Fora (2010). Especialista em Religiões e religiosidades afro-brasileiras (2014). Mestrado em Ciências Sociais pela Universidade Federal de Juiz de Fora na linha de pesquisa Diversidades e Fronteiras Conceituais, tendo como orientador o Prof. Dr. Carlos Perez Reyna (2017). Atualmente, doutorando em História Social, pela Universidade Federal da Bahia (UFBA).

\section{Gustavo José Jaques de Melo}

Graduado em Composição e Regência (2008) e Licenciatura em Música (2017) pela Universidade Federal da Bahia - UFBA. Possui Mestrado em Etnomusicologia (2017) também pela UFBA em pesquisa cujo tema foi "O samba duro: O Samba Junino e o São João de Salvador"; que buscava compreender a construção musical nessa manifestação. Entrou no curso de composição e regência na Escola de Música da UFBA em 2002, onde fez diversas pesquisa através do PIBIC/CNPQ sobre músicas do universo afroreligioso de Salvador. Foi diretor, com positor e arranjador no projeto Bahiamérica com a gravação de vídeo documentário. Lançou em julho de 2013 o CD Gustavo de Melo e o Tambor de Corda que traz influências da música 
afro-religiosa trazendo para o violão os toques dos tambores, codiretor musical e produtor do CD da Banda Vovó do Mangue da cidade de Maragogipe - Bahia, atuando como guitarrista, arranjador, compositor e cantor.

\section{Helen Campos Barbosa}

Doutoranda pelo Programa de Pós-Graduação em Comunicação e Cultura contemporâneas - POSCOM/UFBA. Mestre pelo Programa de Pós-Graduação em Crítica Cultural / Pós - Crítica pela Universidade do Estado da Bahia UNEB, é especialista em Jornalismo Cultural e possui graduação em Comunicação Social - Habilitação Jornalismo em Multimeios pela Universidade do Estado da Bahia (2008). Jornalista e educomunicadora já coordenou projetos em escolas públicas incentivando a apreciação da cultura e arte brasileiras bem como o protagonismo juvenil nas mídias. Coordenou o Projeto Nos meios - Protagonismo juvenil na construção de Programas Culturais de TV e ministra oficinas em escolas e ONGs como o Espaço Cultural Pierre Verger em Salvador - BA. Tem interesse nas relações de gênero, sexualidade e raça no contexto de produção e fruição estético musicais, nos entrelaçamentos entre estética e política bem como entre cultura e tecnologia.

\section{Katharina Döring}

Graduação em Educação Musical (2000) e mestrado em Etnomusicologia (2002) pela Universidade Federal da Bahia; doutorado em Educação (2011) pela Universidade Siegen, Alemanha. Desde 2002 professora assistente/adjunta da Universidade do Estado da Bahia (UNEB) na área de Arte-Educação e Educação Musical. Pesquisadora do Samba de Roda do Recôncavo Baiano desde 2001, com vários projetos e publicações de pesquisa, extensão. Trabalha na interface de Etnomusicologia, Educação Musical, Artes. Coordenadora do 1. e 2. Fórum de Educação Musical da Bahia (FEMBA 2012 e 2013). Pesquisadora do grupo de pesquisa Núcleo de Tradições Orais e Patrimônio Imaterial (NUTOPIA). Desde de 2013 professora colaboradora no Mestrado Profissional em Musica (PPGPROM) da EMUS-UFBA na área de educação musical. Autora do livro "Cantador de Chula - o samba antigo do Reconcavo baiano" (2016). A partir de 2016, atua na Pós-Critica - UNEB, Campus II na disciplina “Culturas 
Populares e Tradições Orais". Coordenadora do Dossiê 48 "Musica e Educação - uma relação interdisciplinar e pluricultural”, Revista da FAEEBA - 2017. Projeto de pesquisa "Koringoma - caminhos para uma educação musical afrobrasileira” desde de 2017.

\section{Luan Sodré de Souza}

Músico, violonista, pesquisador e educador musical. É licenciado em Música pela Universidade Federal da Bahia - UFBA, mestre e atualmente doutorando em Educação Musical pelo Programa de Pós-Graduação em Música da mesma instituição - PPGMUS/UFBA. Atualmente, como doutorando, integra o grupo de pesquisa VIEMUS (Violão e Educação Musical), que sob a coordenação da Professora Doutora Cristina Tourinho, têm reunido investigações sobre Educação musical e, ensino e aprendizagem do violão. Integra o Baobá: grupo de estudos em ancestralidade e pensamento de(s)colonial. Integra a gestão 2017-2019 do FLADEM seção Brasil, como representante do estado da Bahia. Atualmente é professor auxiliar do Departamento de Letras e Artes da Universidade Estadual de Feira de Santana (UEFS), atuando no Curso de Licenciatura em Música.

\section{Marcus Bernardes de Oliveira Silveira}

Graduado em Ciências Sociais na modalidade Bacharelado pela Universidade Federal do Recôncavo da Bahia (2014). Licenciado pelo Programa Especial de Formação Docente, com habilitação em Sociologia, pela Faculdade Regional de Filosofia, Ciências e Letras de Candeias (2018). Mestre em Antropologia Social pela Universidade Federal de Goiás (2016). Professor substituto de Ciências Sociais na Universidade Federal do Recôncavo da Bahia no período de 2016 a 2018, no Centro de Artes, Humanidades e Letras (CAHL). Membro do Laboratório de Ensino de Ciências Sociais (LABECS/UFRB). É Professor de Ciências Sociais no Centro Universitário UniFG, localizado na cidade de Guanambi-BA, lecionando em diversos cursos de graduação. Tem experiência nas áreas de Sociologia e Antropologia, atuando principalmente nos seguintes temas: Culturas Populares, Pensamento Social Brasileiro e Ensino de Ciências Sociais. 


\section{Nina Graeff}

Possui graduação em Comunicação Social (PUCRS, 2005), graduação em Música (UFRGS, 2009), pelo Conservatório Nacional de Estrasburgo (França, 2009), mestrado em “Transcultural Music Studies" - Instituto de Musicologia de Weimar-Jena (Alemanha, 2011). É doutora em Antropologia e Educação na Universidade Livre de Berlim, com bolsa do programa internacional de doutorado "Interart Studies", 2017. Foi pesquisadora do projeto internacional “Global Music Database"; (2011-2012) em Weimar. Tem contribuído para o debates em torno das convenções da UNESCO sobre Patrimônio Cultural Imaterial e Diversidade Cultural. Tem experiência nas áreas de Antropologia Cultural e Etnomusicologia, atuando principalmente nos seguintes temas: música; políticas, hábitos e práticas culturais; patrimônio imaterial; transculturalidade; cultura e religião afro-brasileira; antropologia do corpo / teoria da prática. Autora do livro “Os Ritmos da Roda” EDUFBA, 2015.

\section{Sormani Silva}

Mestre pelo Programa de Pos-Graduação em Relações Etnicorraciais do CEFET-RJ Especialização em Educação e História do Negro na Sociedade Brasileira -PENESB/UFF. Bacharelado e Licenciado em História pela Universidade Federal Fluminense (1996). Doutorando em Memória Social Unirio.

\section{Tiago de Oliveira Pinto}

Titular da cátedra de "Transcultural Music Studies"; do Instituto de Musicologia das universidades Weimar e Jena, Alemanha. Professor Colaborador do Programa de Pós-Graduação em Antropologia Social da Universidade de São Paulo (USP). É Doutor pela Universidade Livre de Berlim (1989). Foi professor de Etnomusicologia do Instituto de Musicologia da Universidade de Hamburgo de 2006 a 2008 e professor do Departamento de Antropologia da Universidade de São Paulo de 2000 a 2005. Foi presidente da Associação Brasileira de Etnomusicologia (ABET) de 2004 a 2006. Antropólogo, musicólogo, curador de exposições culturais e de artes plásticas, produtor musical e de cultura. Autor e co-autor de vários livros, revistas e 
SOBRE AS AUTORAS E OS AUTORES

artigos sobre o samba brasileiro, assim como músicas africanas e afrobrasileiras em geral. 